\title{
Reproductive adaptations to high densities in social mammals
}

\author{
WILLIAM Z. LIDICKER, JR. ${ }^{1 *}$ \\ 'Professor of Integrative Biology Emeritus and Curator of Mammals Emeritus, University of California Berkeley, CA 94720, U.S.A. \\ ${ }^{*}$ Corresponding author
}

\begin{abstract}
An overview of population density control in social mammals sets the framework for examining reproductive responses to increasing population densities. We begin by honoring John B. Calhoun who played a major role, starting about 70 years ago, in correcting the conventional wisdom of the time that population control was all about adjusting mortality rates. Reproduction was considered a constant, and emigration was viewed as a component of mortality. His research was mostly on domestic and feral populations of Rattus norvegicus and Mus musculus for which he built complex arenas that could house thousands of inhabitants. In addition, he constructed elaborate living quarters in the alleyways of Baltimore. For the captive populations, he would individually mark all the inhabitants so that he could identify them and observe their behavior. Eight examples of his research publications are described. He was able to document a list of reproduction related behaviors that are the main focus of this essay, and clearly demolish the simplistic notion that reproduction is a constant. A summary of some of the major issues that encompasses the science of population growth and regulation is provided. There follows a series of 19 examples of non-Calhoun publications that cover many more species of social mammals, including humans. A comprehensive list of the many negative adaptations involving reproductive processes are documented for the 27 publications reviewed confirming that in many species reproductive constraints are non-trivial. There follows a brief discussion that attempts to create a cohesive whole for this intellectual adventure.
\end{abstract}

En este articulo, se presenta una reseña histórica sobre estudios de control de densidades poblacionales en mamíferos sociales, lo que establece un marco de referencia para examinar las respuestas reproductivas al incremento en densidades poblacionales. Comenzamos honrando a John B. Calhoun, quien, comenzando unos 70 años atrás, y jugó un papel importante pues corrigió las creencias convencionales de la época de que el control de la población se basaba solamente en el ajuste de las tasas de mortandad. La reproducción se consideraba una constante, y la emigración se consideraba un componente de la mortalidad. Sus investigaciones se centraron principalmente en poblaciones domésticas y silvestres de Rattus norvegicus y Mus musculus, para las que construyó arenas complejas que podían albergar hasta miles de individuos; además, construyó elaboradas viviendas en los callejones de Baltimore. Para las poblaciones cautivas, marcaba individualmente a todos los habitantes para poder identificarlos y observar su comportamiento. Se describen ocho ejemplos de sus publicaciones de investigación. Calhoun pudo documentar una lista de comportamientos relacionados con la reproducción que son el foco principal de este ensayo y claramente desmantelan la simplista noción de que la reproducción es una constante. Se proporciona un resumen de algunos de los principales temas que abarca la ciencia del crecimiento y la regulación de la población. A continuación, se presenta una selección de 19 otras publicaciones que cubren muchas más especies de mamíferos sociales, incluyendo los humanos. En las 27 publicaciones examinadas se documenta una lista completa de las numerosas adaptaciones negativas que entrañan los procesos de reproducción, lo que confirma que, en muchas especies, las limitaciones en materia de reproducción no son triviales. Por último, se presenta una breve discusión que intenta crear un todo cohesivo para esta aventura intelectual.

Keywords: cannibalism; density controls; dispersal; ecology; homosexuality; J. B. Calhoun; reproduction constraints; social behavior; social groups; stress.

๔ 2020 Asociación Mexicana de Mastozoología, www.mastozoologiamexicana.org

\section{Introduction}

Ecologists understand that as populations grow, negative forces gradually accumulate that eventually stop growth or even precipitate population crashes. There are three possible forces that either separately or in various combinations lead to growth slowing and eventually cessation. These are increasing mortality, decreasing reproduction, and emigration rates exceeding immigration (Cole 1948; Lidicker 1985; Park 1946). In a global perspective, only the first two of these are relevant. This essay explores the various ways that reproduction in highly social mammals respond to increasing densities. For a conceptual framework of population regulation in mammals developed in a historical narrative see Lidicker $(1983,1994)$.

Mammals like all other organisms require multiple resources for their success. For mammals these include food, adequate shelter, protection from predators and parasites, a physical and biotic environment or habitat appropri- ate to their needs, and opportunities to reproduce. If a species reproduces sexually, like mammals, a further requirement is a suitable social environment that can then supply the necessary sex partners. In some cases, success requires more than one habitat. A species of bat for example may need a cave in the winter and a forest at other times of the year, or a pinniped will rotate on an annual cycle between a safe haul out site and the open ocean. A rodent may use an agricultural field in the summer but require a more sheltered burrow at other times.

Another ecological principle that needs including in this brief outline of demographic processes is the so-called Allee effect (Lidicker 2010), also termed anti-regulation. It turns out that there are sometimes forces that operate in directions opposite the regulating ones outlined above. For example, Allee effects may promote growing populations to increase faster as numbers increase rather than more slowly. Eventually regulating influences will over- 
come the anti-regulating ones and growth does stop. Also, the Allee effect can operate at low densities. In this situation, growth promoting forces ordinarily increase as numbers decrease, but if anti-regulating forces are present a population will instead continue to decline, and then if it drops below a certain threshold density, it will continue to decline to extinction.

Given this brief outline of demographic processes, I now focus on possible reproductive declines at high densities, especially in mammals. Of course, mammals are subject to the full suite of negative forces outlined above. However, there is increasing evidence that mammals have mechanisms for reducing reproductive success at high densities that are not directly caused by the usual resource and habitat limitations. So far, the evidence for this comes from highly social species, and therefore we can surmise that it may be somehow related to overly intense or overly stressful social interactions at high densities.

In the early days of modern population ecology, that is going back about seven decades, it was widely proclaimed that reproductive activities did not decline with increasing densities, but instead population control was largely an effect of mortality increases. Even dispersal from high density areas was thought to not be very important because dispersers were supposedly quick to be converted into mortality statistics (Lidicker 1978). It was in this intellectual environment that John Calhoun began his experimental work on mammal population dynamics starting in about 1949 and extending to at least 1963. Some research was done on wild populations of rodents (Calhoun 1962a, 1962 b), but mostly he focused on captive colonies living in large and complex enclosures that, sometimes housed individuals numbering in the thousands. In this way he could observe and analyze their social behavior in detail, and match it with reproductive activities, lifespan, causes of mortality, etc. The species he used were Rattus norvegicus, both wild and domesticated, and various strains of Mus musculus.

A John B. Calhoun Sampler. The first part of this document is written as a tribute to Calhoun in appreciation for his pioneering contributions to population ecology and social behavior of mammals. His contributions have been truly monumental. Here is a chronologically arranged sample of Calhoun's publications $(n=9)$ with comments explaining their relevance to our current topic (see publication index for full citations).

1. Calhoun (1949). Observations of five rat colonies in very large pens constructed in Baltimore alleys and streets. The rats used in this experiment came from a small island and so were judged to be relatively inbred. The rate of reproduction was negatively related to the density of the population. New born young from mothers with poor nutrition failed to survive. The extent to which fetal nutrition was sub-maximal slowed population growth. Lactating females were particularly aggressive toward low ranking females. Slow growing females received 10 times more wounds than those fast growing. Larger and more dominate females raised 10 litters from 12 pregnancies while subordinate females weaned a maximum of one litter. The conclusion is that social conditioning may be a potent factor in population control among mammals.

2. Calhoun (1950). This paper reports results using the same enclosures as the previous paper. Five pairs of rats were used to initiate the colony. Rats raised in a suboptimal part of the enclosure weighed less, were more frequently wounded, conceived less often, and only rarely raised a litter successfully compared to other rats. That is, the rats living in the less favorable areas were "socially sterilized." Some of these females had young, but they survived only a few days. This example illustrates the potential importance of micro-habitat quality in influencing reproductive success.

3. Calhoun (1952). Social stability through formation of social groups led to successful reproduction and decreased mortality, but eventually population growth restricted use of all the available space. This, along with groups lacking well integrated dominance hierarchies caused social instability that reduced the frequency of conceptions. Moreover, very few of the young born lived to weaning, and those few that did survive had only a slim chance of breeding. The importance of the Allee Effect at both high and low densities was also reported.

4. Calhoun (1956). Mouse strains differed in their susceptibility to social stresses. Adult males were the major stressors of adult females, and if new mothers were socially stressed by males, they ate their young shortly after birth. Stress also occurs if the social environment becomes more complex, and this also can disrupt maternal care behavior. Adjustment to more complex social and/or physical environments as well as higher densities is sufficient stress to disrupt maternal behavior. This results in both failures to conceive and destruction of litters. In one experiment, a new colony consisting of 14 adults and 15-day-old young were all dead within 75 days apparently a consequence of fighting. Lower densities were achieved by dispersers forming very small colonies presumably in order to establish persistent and positive social relationships quickly, and this generated an overall lower density (number of individuals per square yard).

5. Calhoun (1961). One colony of domestic rats grew for four months to peak density, producing three generations of young organized into complex social structures. Relevant features were persistent within litter social associations, harem formation, homosexuality, and stable social groups.

6. Calhoun (1962a). This research involved laboratory rats and featured acutely abnormal behavior leading to extinction. Initially there were 80 individulals in 4 pens. All the rats were in good health and were at the prime of life age. They produced fewer litters than expected; 
none of the offspring lived to maturity; males were more homosexual or "pansexual" (made sexual advances to males,females not in estrous and juveniles); some mles were indifferent to all other individuals, even females in estrous. These homosexual males were ignored by other rats and seemed perfectly healthy. There were also some males labeled "probers" These males were hyperactive, hypersexual, and homosexual, and some became cannibalistic; only half of newborns survived. The colony continued to deteirorate.

7. Calhoun (1962a). The colony in this study took four months to reach peak density; it featured territoriality, harem formation, social stability, and homosexuality. Reproduction was inhibited in two ways by social stresses: 1) a reduced ability to rear the young such that no young survived to maturity even though the number of conceptions (placental scars) was not reduced, and 2) a reduction in the ability of fertilized eggs to develop following implantation. These two phenomena are believed to be the most important ones through which population growth was inhibited in the presence of abundant food and an sample space for the elaboration of new burrows.

8. Calhoun (1962b). When a population of laboratory rats is allowed to increase in a confined space, the rats develop acutely abnormal patterns of behavior that can even lead to the extinction of the population. Many of the females were unable to carry pregnancy to full term or to survive the birth of their litter. If they did successfully deliver their litter they failed in their maternal duties, and the litter did not survive. Males mostly developed behavioral disturbances ranging from sexual deviations to cannibalism, and from frenetic over-activity to pathological withdrawal from social interactions. The sex ratios of social groups became aberrant, and infant mortality reached $96 \%$ in some social groups. Of special interest, many adult males assumed various pathological behaviors. Some became aggressive to all other individuals regardless of sex or age. Many became homosexual, and some were "pansexual" as they did not discriminate among sexes or ages, but sexually assaulted one and all. Others moved through the communities ignoring all other rats, even females in estrous, and if attacked they did not attempt to retaliate. Some adult males adopted a new type of behavior that the author named "probers". They were hyperactive, hypersexual, homosexual, and for some cannibalistic. When they did encounter an estrous female, they ignored all the usual courtship procedures that are typically performed. Obviously social groups that developed in this way did not have a happy future.

9. Calhoun (1963). The author postulated that the natural or basic group size for social mammals is 12 . If population growth causes this optimal group size to be exceeded, frustration increased in concert with increasing population density, and this in turn lead to increasing presence of males that deviate behaviorally from the usual norm, homosexuality being a common variant. He also claimed that Vitamin A reduced social group stress. Significantly, the author also suggested that human social behavior is consistent with the basic structure that is found in other social mammals investigated, including the occurrence of aberrant reproductive behaviors such as homosexuality.

Other relevant contributions. Here are brief descriptions of 19 publications, not including any of those authored by John Calhoun. Mostly they are about small mammal populations, both in confinement and in free-ranging that illustrate the diversity of ways that reproduction influences population regulation. In order to honor the historical framework of this document, the 19 publications are arranged in chronological order of their publication date, starting with the oldest one.

1) Anderson (1961), species featured: House mouse (Mus musculus). The concentration is on house mice living in the more traditional agricultural environments in which favorable sites with abundant resources are scattered widely. If immigration pressure to a favorable site is intense and resources are compromised, the social stability of the social group will be damaged, precipitating gonadal inhibition, cannibalism of young, and nest destruction.

2) Barbehenn (1961), species featured: laboratory rat (Rattus norvegicus) explores the relationship between the tendencies for newly weaned laboratory rats to explore their environment depending on the size of the litter in which they were raised for 30 days after birth. Members of litters of 12 began to explore within one or two days after the chambers were opened. Those from litters of 3 were not all exploring until 65 days of freedom. Those from litters of 6 were intermediate in their enthusiasm for exploration. The large litter cohorts were also the most aggressive of the three categories in feeding. There can be no doubt that the weanlings from litters of 12 would have the best chance of initiating their own reproductive fitness promptly. After about 90 days the exploratory behavior of all three categories of litter size had equilibrated.

3) Lidicker (1965), describes a comparative study in population regulation using four species of rodents that were introduced separately into large complex chambers with multiple levels, complex passageways, nest chambers, feeding areas, etc. The species tested were: Mus musculus, Peromyscus maniculatus, P. truei, and Oryzomys palustris. Two adults were introduced into each of the complex chambers supplied with excess food and water. The experiments lasted from one year to 2.5 years. Six populations were observed. The two $P$. maniculatus and one Mus populations exhibited density plateaus due to seasonal cessation of reproduction combined with much nestling mortality. Also, sex ratios became biased in favor of males, and these males had 
extensive wounding and other signs of stress. The Oryzomys and $P$. truei populations experienced much infant mortality and a small but persistent amount of adult mortality. These two species do not ordinarily experience high densities, and so it seems that they have not evolved mechanisms to deal with such densities and therefore resort to killing when densities are high.

4) Lidicker (1976), concerns a study of house mice (Mus musculus) living in two large and complex enclosures. The colonies were established by introducing 15 pairs of adults to each enclosure. Both grew rapidly to about 2,000 individuals in one and somewhat less in the other. The mice became arranged into eight social groups. In both populations successful dispersal among groups was very rare. In fact, the dispersing weaned young almost invariably returned to their home group. Three attempts were made to introduce additional mice. This was only successful when the newcomers were able to establish a new group in disputed areas between established groups. Continued growth of existing groups was prevented by reproductive inhibition and high neonatal mortality. There was massive inhibition of sexual maturation in young mice as well as complete regression of reproductive tracts in most adults. Such mice tended to get fat and there was a negative relationship between obesity scores and the size of the seminal vesicles. Moreover, there was widespread failure of adults to become reproductively active and a widespread loss of neonates during the first three days after birth. Older mice that had matured sexually tended to regress from reproductive competence in both sexes.

5) Lidicker (1979). Subject species: California vole (Microtus californicus). These voles were introduced into two large enclosures with natural grassland vegetation cover. Population founders were two pairs of adult voles in each enclosure. Initial fighting reduced the founders to one pair in one case and one male and two females in the other. Adequate food and water were supplied throughout. The populations grew rapidly with all three of the surviving founders breeding successfully. However, neonatal mortality was high although litter size was unaffected. A large percentage of the adults of both sexes were initially involved in the population growth. However, by half way through the about one-year experiment, a high percentage of the adults failed to mature sexually, and the three founding voles abruptly disappeared.

6) Lidicker (1980). Subject species: California vole (M. californicus) summarizes information from a number of field and captive studies on the social biology of the California vole. Increasingly high densities suffer increasing proportions of sexually inactive adults. The inhibitory effects are stronger in males than in females. In one high density year only 20 percent of the males were reproductively active. Over a three-year study males weighings less than 35 grams were uniformly inactive sexually. Those more than $45 \mathrm{~g}$ were all reproductively active. This effect occurred in both enclosures and natural habitats. In a year of peak densities, only $20 \%$ of males were reproductively competent. This syndrome also occurs in Microtus agrestis.

7) Cockburn and Lidicker (1983). Subject species: California vole ( $M$. californicus). This research was done in natural grasslands. The largest males in four monitored populations tended to move to the lowest quality grids which had few adult females, and therefore contributed little to reproduction in the population collectively.

8) Lidicker and Ostfeld (1991). Subject species: (M. californicus). This report is on an unusual behaviorally caused reduction in reproductive output in the California vole, and by extrapolation likely also occurring in other species of Microtus that exhibit multiannual cycles of abundance. As populations approach their peak densities, it was observed that the largest and presumably the oldest males accumulate in the poorest habitat patches. Adult females are rarely found in these places and hence a major depression in potential reproductive output occurs. One could speculate that selection is favoring the fitness of previous offspring of these large males as population densities are approaching a crash in numbers. Or perhaps these large males are merely avoiding aggression from younger adult males.

9) Lidicker (1994), provides an overview of population dynamics with an emphasis on mammals, in an historical perspective.

10) Lidicker and Batzli (1999). Subject species: Singing vole (M. miurus) occurs in the northwestern most part of North America where it lives in well drained tundra and subalpine zones. Their density fluctuates strongly with declines associated with poor reproduction. A few pregnancies can occur at any time of the year but they are rare at any time, presumably as a result of chronically scarce food resources.

11) Lidicker et al. (2000). Subject species: Snowshoe hare (Lepus americanus). Observations of genetic changes within a single 11-year population cycle of the snowshoe hare suggests the possibility that such genetic shifts could be an additional influence on modifying reproductively relevant behaviors.

12) Lidicker (2009), provides an overview of population dynamics as of a decade ago, and includes a look into the past, and makes projections for the future. Most importantly it reveals how the trend over the past seven decades has seen a gradually increasing level of complexity in the context of ecological research (up to the ecoscape level). In particular, the trend has revealed increasing examples of reproductive responses to high population densities.

13) Schoepf and Schradin (2012). Research subject is the African striped mouse (Rhabdomys pumilio). This species is socially flexible and can live successfully in 
groups or solitarily. This research attempts to understand how individuals cope with and profit by this flexibility. There are seasonal changes, as well as unanticipated environmental fluctuations, and possible genetic changes. There is some evidence that individuals begin to develop behaviors appropriate to anticipated dispersal targets before they actually move. For example, mice anticipating a move become more active before actually dispersing. Aggressive behavior is correlated positively with body weight.

14) Schradin and Lindholm (2012). Subject: African striped mouse ( $R$. pumilio). Flexible social behavior allows for adaptations to changing conditions, and provides especially for conditions favorable for reproduction. Behavioral changes are driven by sex hormones. Most dispersers are males. High population density favors group living and philopatry.

15) Raynaud and Schradin (2013). Subject: African striped mouse. Breeding is stimulated by high blood levels of prolactin. This is normally controlled by photoperiod. However, unusually favorable food conditions or unseasonable rainfall can also cause an increase in prolactin and can trigger breeding behavior.

16) Manjerowic and Waterman (2015). Subject: Cape ground squirrel (Xerus inauris). Sixty five percent of males that attend to a female in estrous successfully copulate, and this is the same for resident and dispersing males. However, $70 \%$ of completed copulations do not result in any offspring. On the population level, only $28.4 \%$ of males succeed in fathering offspring. Normal litter size is one, and in the rare cases of two embryos, each fetus has a different father. Typically, these squirrels live through two breeding seasons.

17) Nater et al. (2018). Subject: African striped mouse. Modeling study focused on effects of environmental temperatures, food supply, and density changes on reproduction. Strong density feedbacks allowed reproduction to stabilize densities and recover from detrimental crashes. There is no mention of how density translates functionally into variations in reproduction, but food supply is the primary driver. This study is a classic example of density-dependent control of demographics.

18) Wadman (2018). Subject species: (Homo sapiens) describes a paper published in Plos One by Lisa Littman that describes a sudden increase in gender dysphoria among human teens and young adults. It is of course controversial and it has attracted much critical commentary. Critics have claimed that the paper was not good science and was politically biased. One writer even made the inexplicable comment that the article was "anti-gay." Littman's paper includes a graph showing an exponential growth in transgender identities of both sexes from 2009 to 2016. Wadman concludes that Littman's paper points to a clearly real phenomenon.
My suggestion on this controversial paper is that it is arguably "pro-gay" since it adds understanding to the current reality.

19) Van Cann et al. (2019). Subject: Bank voles (Myodes glariolus). Early life of fathers has major fitness effects on offspring. These influences lead to a mechanism for fathers to transmit environmental information to their offspring. That then promotes adaptation to current density conditions. Experiments were carried out in outdoor experimental cage systems that were semi-natural. Reference is made to earlier studies on maternal social stresses leading to reduced body mass of offspring.

\section{Discussion}

In this treatise I have tried to amalgamate basic population ecology with a comprehensive look at the role of reproduction in contributing to regulation of population numbers with an emphasis on social mammals. The importance of mortality in this regulation process is widely acknowledged, and dispersal is increasingly investigated for its role in spatially organizing and thereby stabilizing ecological communities, and therefore in stopping population growth. The literature seemed to point to highly social species as likely to have the most complex and interesting possibilities for finding controls on reproductive functions. Moreover, this focus also includes our own species which with our runaway population growth and the myriad of related problems definitely needs to be included. I think this remains a fascinating and potentially rewarding frontier for research, and I hope that this paper will stimulate research on the role of social behavior in mammals especially with a focus on its demographic and conservation impacts. Rewarding research opportunities abound.

While it is true that emigration from high density enclaves with or without increasing mortality rates can in principle stop population growth and even initiate population declines it is also true that reductions in reproductive outputs can also accomplish this. And, of course all combinations of the three relevant demographic processes can and do occur. Moreover, all of these possibilities can be found in captive populations as well as those free ranging.

\section{Selected 16 examples of social behavior/density} coactions. Our goal is to document and understand the nature of both positive and negative behavioral synergisms. With goal in mind, here is a list of 16 reproductive processes found in this short literature survey of 27 publications that have been observed to have negative effects on population growth. They are described in more detail both in the section of papers by John Calhoun and in the section on "other relevant contributions":

a. Failure of pregnancy to go full term; neonates all dead by three days post-partum;

b. Spatial segregation of adults with largest males accumulating in the poorest habitat patches, adult females mostly absent; failure of young to reach sexual maturity; 
c. Lactating females aggressive toward low-ranking females who raised only one litter compared to 10 by dominant females over the same time period;

d. High densities cause de-stabilization of social groups that then have few conceptions, and those few young that do survive have only a slim chance of breeding;

e. Harem formation reduces female mating, and homosexuality reduces male breeding;

f. Social instability and accompanying stress lead to no young surviving to sexual maturity, and pregnancies not reaching full term;

g. Some females are unable to survive parturition; successful parturition may be followed by death of the litter; males can become cannibalistic;

h. Social instability leads to no young surviving to maturity, females may be unable to survive parturition or maybe followed by successful parturition may be followed subsequently by death of the litter;

i. Massive inhibition of sexual maturation in young mice and complete regression of reproductive tracts;

j. A negative relation between obesity scores and the size of seminal vesicles;

k. Older mice that have matured sexually tend to regress from reproductive competence in both sexes;

I. Intense social pressure causes social groups to become unstable leading to gonadal inhibition, cannibalism of young, and nest, destruction;

$\mathrm{m}$. Sex ratios become biased in favor of males leading to extensive wounding and other signs of stress;

n. Species that normally do not experience high densities resort to killing when densities are high;

o. As the population increases, the fraction of the adult population that is not-reproductive increases, males are more subject to reproductive loss than females;

p. The timing of exploration by neonates is positively correlated with litter size in litters varying from three to twelve and those from large litters are the most successful in integrating into the social environment and beginning their reproductively active life.

\section{Acknowledgments}

It is a special privilege to be asked to contribute to a publication in honor of my friend and colleague Sydney Anderson. Our professional careers were closely intertwined, especially with respect to our joint involvement with the American Society of Mammalogists. I also thank Therya's editorial team and the invitation to participate in this volume.

\section{Literature cited}

Anderson, P. K. 1961. Density, social structure, and nonsocial environment in house-mouse populations and the implications for regulation of numbers. Transactions of the New York Academy of Sciences 31:447-451.

Barbehenn, K. R. 1961. Some effects of litter size on social behavior in laboratory rats. Transactions of The New York academy of Sciences 23:443-446.
Calmoun, J. B. 1949. A method for self-control of population growth among mammals living in the wild. Science 109:333-335.

Calmoun, J. B. 1950. The study of wild animals under controlled conditions. Annals New York Academy of Sciences 51:1113-1122.

CaLhoun, J. B. 1952. The social aspects of population dynamics. Journal of Mammalogy 33:139-159.

CaLhoun, J. B. 1956. A comparative study of the social behavior of two inbred strains of house mice. Ecological Monographs 26:81-103.

Calmoun, J. B. 1961. Determinants of social organization exemplified in a single population of domesticated rats. Transactions of the New York Academy of Sciences 23:437-442.

Calmoun, J. B. 1962a. The Ecology and sociology of the Norway Rat. U.S. Department of Health, Education, and Welfare. Public Health Service publication 1008:1-288.

CaLhoun, J. B. 1962b. Population density and social pathology. Scientific American 206:139-148.

CaLmoun, J. B. 1963. The Ecology of aggression - its relationship to frustration and social withdrawal. unpub. doc. Department of Health, Education and Welfare, National Institutes of Health.

Cockburn, A., AND W. Z. Lidicker, JR. 1983. Microhabitat heterogeneity, population ecology of an herbivorous rodent, Microtus californicus. Oecologia 59:167-177.

Cole, L. C. 1948. Population phenomena and common knowledge. Scientific Monthly 67:338-345.

LIDICKER, W.Z.JR. 1965. Comparative study of density regulation in confined populations of four species of rodents. Research in Population Ecology 7:57-72.

LIDICKER, W. Z., JR. 1976. Social behavior and density regulation in house mice living in large enclosures. Journal of Animal Ecology 45:677-697.

LIDICKER, W. Z., JR. 1978. Regulation in numbers in small mammal populations - historical reflections and a synthesis. Pp 163-166 in Populations of small mammals under natural conditions (Snyder, D. P., ed.). Pymatuning Laboratory of Ecology, Special Publications.

LIDICKER, W.Z, JR. 1979. Analysis of two freely-growing enclosed populations of the California vole. Journal of Mammalogy 60:447-466.

LIDICKER, W. Z., JR. 1980. The social biology of the California vole. The Biologist 62:46-55.

LIDICKER, W.Z., JR. 1983. Regulación poblacional de mamíferos. Medio Ambiente 6:3-11.

LIDICKER, W. Z., JR. 1985. Population structuring as a factor in understanding microtine cycles. Acta Zoologica Fennica 173:23-27.

LIDICKER, W. Z., JR. 1994. Population Ecology, 75 years of Mammalogy (1919-1994). Pp. 323-347 in Special Publication of the American Society of Mammalogists 11:1-443.

LIDICKER, W. Z., JR. 2009. Population dynamics of mammals. An overview of the past and a glimpse into the future. Mammalian Biology 74S:4-5.

LIDICKER, W.Z, JR. 2010. The Allee effect: its history and future importance. The Open Ecology Journal 3:71-82.

Lidicker, W. Z., JR. AND G. O. BatzLI. 1999. Singing Vole, Microtus miurus. Pp. 632-633 in Complete Book of North American Mammals (Wilson, D.E. and Ruff, S., eds.). Smithsonian Press, Washington, U.S.A. 
LIDICKER, W. Z., JR., AND R. S. OstrelD. 1991. Extra-large body size in California voles: causes and fitness consequences. Oikos 61: 108-121.

Lidicker, W. Z., JR., J. O. WolfF, AND R. A. Mowrey. 2000. Genetic changes in a cyclic population of snowshoe hares. Ecoscience 7:247-255.

Manjerovic, M. B., and J. M. Waterman. 2015. "Failure to launch": is there a reproductive cost to males living at home? Journal of Mammalogy 96:144-1050.

Nater, C. K., J. van Benthem, C. I. Canale, C. Schradin, and A. Ozgul. 2018. Density feedbacks mediate the effects of environmental change on population dynamics of a semidesert rodent. Journal of Animal Ecology 87:1534-1546.

PARK, T. 1946. Some observations on the history and scope of population ecology. Ecological Monographs 16:311-320.

Raynaud, J., AND C. Schradin. 2013. Regulation of male prolactin levels in an opportunistically breeding species, the African striped mouse. Journal of Zoology 290:287-292.

Schoepf, I., and C. Schradin. 2012. Differences in social behavior between group-living and solitary African Striped mice, Rhabdomys pumilio. Animal Behaviour 84:1159-1167.

Schradin, C., A. K. Lindholm, J. Johhannesen, I. Schoepf, C. H. Yuen, B. König, And N. Pillay. 2012. Social flexibility and social evolution in mammals: a case study of the African striped mouse (Rhadomys pumilio). Molecular Ecology 21:541-553.

Van Cann, E. Koskela, T. Mappes, A. M Mikkonen, M. Mokkonen, AND P. C. Watts. 2019. Early life of fathers affects offspring fitness in a wild rodent. Journal of Evolutionary Biology 32:1141-1151.

WADMAN, M. 2018. Rapid onset of transgender identity ignites storm. Science 361:958-959.

Associated editor: Jorge Salazar Bravo

Submitted: August 6, 2020; Reviewed: August 25, 2020;

Accepted:September 17, 2020; Published on line:September 23, 2020. 